\title{
On Flow Diversion: The Changing Landscape of Intracerebral Aneurysm Management
}

\author{
(D)A.A. Dmytriw, (D). Phan, (D).M. Moore, DV.M. Pereira, (D)T. Krings, and (D) A.J. Thomas
}

\begin{abstract}
SUMMARY: Uptake of flow-diverting technology is rapidly outpacing the availability of clinical evidence. Most current usage is off-label, and the endovascular community is nearer the beginning than the end of the learning curve, given the number of devices in development. A comprehensive overview of technical specifications alongside key outcome data is essential both for clinical decision-making and to direct further investigations. Most-studied has been the Pipeline Embolization Device, which has undergone a transition to the Pipeline Flex for which outcome data are sparse or heterogeneous. Alternative endoluminal devices do not appear to be outperforming the Pipeline Embolization Device to date, though prospective studies and long-term data mostly are lacking, and between-study comparisons must be treated with caution. Nominal technical specifications may be unrelated to in situ performance, emphasizing the importance of correct radiologic sizing and device placement. Devices designed specifically for bifurcation aneurysms also lack long-term outcome data or have only recently become available for clinical use. There are no major studies directly comparing a flow-diverting device with standard coiling or microsurgical clipping. Data on flow-diverting stents are too limited in terms of long-term outcomes to reliably inform clinical decision-making. The best available evidence supports using a single endoluminal device for most indications. Recommendations on the suitability and choice of a device for bifurcation or ruptured aneurysms or for anatomically complex lesions cannot be made on the basis of current evidence. The appropriateness of flow-diverting treatment must be decided on a case-by-case basis, considering experience and the relative risks against standard approaches or observation.
\end{abstract}

ABBREVIATION: $M C R=$ metal coverage ratio

$\mathbf{T}$ he Pipeline Embolization Device (PED; Covidien, Irvine, California) was approved by the FDA in 2011 and by the European Medicines Agency (EMA) in 2008 for the treatment of large or giant, wide-neck intracranial aneurysms of the internal carotid artery from the petrous to the superior hypophyseal segments. ${ }^{1}$ Currently, this is the only device approved in the United States. In Europe, there are additional options, including the PED, Silk flow diverter (Balt Extrusion, Montmorency, France), Flow-Redirection Endoluminal Device (FRED; MicroVention, Tustin, California), p64 (phenox, Bochum, Germany), Surpass Streamline (Stryker Neuro-

Received October 26, 2018; accepted after revision January 25, 2019.

From the Department of Medical Imaging (A.A.D., V.M.P., T.K.), Toronto Western Hospital, University of Toronto, Toronto, Ontario, Canada; Neurosurgical Service (A.A.D., K.P., J.M.M., A.J.T.), Beth Israel Deaconess Medical Center, Harvard Medical School, Boston, Massachusetts; and NeuroSpine Surgery Research Group (K.P.), Prince of Wales Private Hospital, Sydney, Australia.

Please address correspondence to Adam A. Dmytriw, MD, MSc, Department of Medical Imaging, University of Toronto, 263 McCaul St, Toronto, ON M5G 0A6, Canada; e-mail: adam.dmytriw@uhn.ca

- Indicates open access to non-subscribers at www.ajnr.org

三 Indicates article with supplemental on-line tables.

http://dx.doi.org/10.3174/ajnr.A6006 vascular, Kalamazoo, Michigan), and Derivo (Acandis, Pforzheim, Germany). Multiple other endovascular flow diverters are commercially available or in late-stage development, including the endovascular devices Pipeline Flex and Pipeline Shield (Covidien), Tubridge (MicroPort Medical Company, Shanghai, China), and the Endovascular Clip System (eCLIPs; Evasc, Vancouver, Canada). No flowdiverting stent has been approved for use in the posterior circulation, treatment of aneurysmal subarachnoid hemorrhage, or in the anterior circulation beyond the internal carotid artery superior hypophyseal segment. ${ }^{2}$ The term "flow diverter" is arguably a misnomer because it is endothelialization that eventually sequestrates the aneurysm.

Flow-diversion technology has relatively few studies reporting long-term outcomes, though available data suggest that complications beyond 6 months postprocedure are rare. Meanwhile, device technology is evolving rapidly, encompassing advances in the control and precision of device placement as well as growing operator experience and skill, all contributing to greater procedural safety. ${ }^{1}$ As a result, off-label humanitarian usage is increasing well ahead of long-term outcome data or regulatory approval. Challenging indications such as distal anterior or vertebrobasilar aneurysms are increasingly considered for flow diversion, against a 

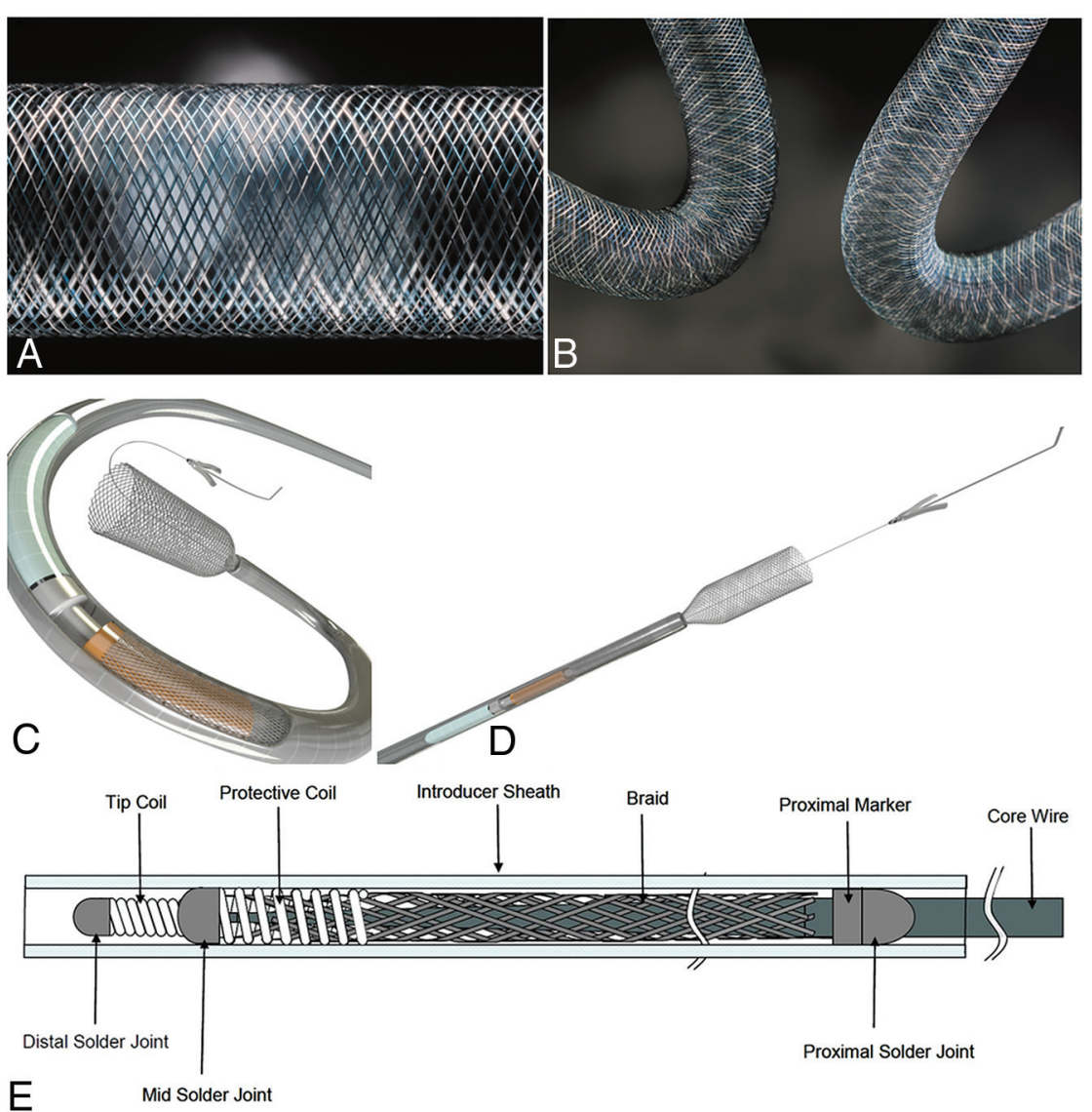

FIG 1. Magnified $(A)$ and flexed $(B)$ views of the Pipeline Embolization Device classic cobalt chromium and platinum tungsten composition. $C$ and $D$, Deployment views of the Pipeline Flex model with a detailed assembly schematic (E). Courtesy of Medtronic/Covidien, Irvine, CA. design does not vary in terms of pore attenuation, its performance is determined by the MCR alone. In this study, the threshold MCR for better 6-month occlusion rates was $23 \%$, markedly less than the nominal value of approximately $30 \% .^{7}$ Use of multiple, shorter devices of differing sizes may minimize transitional zone effects arising from vessel-size mismatch, especially when considering tortuous vessel anatomies ${ }^{6}$; however, this use may also increase complications. ${ }^{8}$ Relatively limited data show that a single device results in complete or near-complete occlusion of most aneurysms, including those at bifurcations, without delayed complications or mortality., ${ }^{9,10}$

A second-generation version, the Pipeline Flex, was approved in Europe in 2014 and the United States in 2015. While the device itself is identical to the original, the delivery system was enhanced to improve device deployment and provide additional safety by incorporating a resheathing feature (Fig 1 and On-line Table 1). ${ }^{11}$ The device is mounted over a stainless steel delivery wire, the distal part being covered by two 3-mm polytetrafluoroethylene protective sleeves, replacing the capture coil of

backdrop of sparse clinical evidence and few guidelines, which make recommendations only for licensed indications. ${ }^{3}$ For some rarer types of aneurysms, obtaining clinical evidence from prospective trials is not feasible. Thus, operators are reliant mostly on empiric medicine. To our knowledge, this represents the most comprehensive review of technical specifications and representative outcome data for flow-diverting stents to inform this fastmoving field.

\section{Conventional Braided Mesh Devices}

The Pipeline Embolization Device comprises a flexible, braided mesh tube of 48 interwoven microfilaments consisting of $25 \%$ platinum-tungsten and 75\% cobalt-chromium-nickel alloy. Porosity approaches the optimal percentage of $70 \%$, depending on sizing and configuration relative to the aneurysm (On-line Table 1). ${ }^{4,5}$ Studies have shown a predictable parabolic variability in PED porosity based on the parameters of device size, recipient artery size, and device curvature; even modest oversizing led to a marked increase in porosity with a reduction in the metal coverage ratio (MCR), which potentially compromises aneurysm occlusion. ${ }^{6,7}$

Device oversizing and deformation during deployment in patients with ICA aneurysms have been shown to markedly reduce local MCR by $5 \%-7 \%$, correlating with a lower occlusion rate at 6 months. ${ }^{7}$ For identical porosities, a higher pore attenuation is associated with more efficient flow diversion. Because the PED the original version to reduce foreshortening and enable more precise device placement. ${ }^{12,13}$ The distal tip is a soft hydrophilic 0.012 -inch wire, with an angle of $55^{\circ}$ and a proximal platinum marker for visibility. The proximal part of the device lies on a silicone elastomer resheathing pad with a profile of 0.023 inches that is located between 2 platinum markers; the most anterior marker is for resheathing. The pusher wire is a thicker, longer hypotube than that used for the parent device. These modifications are intended to provide multiple and technically less challenging options for precise deployment in different anatomies. ${ }^{12}$

A third-generation version called the Pipeline Flex Embolization Device with Shield Technology (Pipeline Shield) was approved in Europe in 2015. This latest device features the same implant and delivery system as the Pipeline Flex, with the addition of a surface modification comprising a layer of phosphorylcholine covalently bound onto the bare metal strands, with the aim of reducing unwanted thrombogenicity. ${ }^{14,15}$ Similar to most other available endoluminal devices, the PED, Pipeline Flex, and Pipeline Shield are delivered via a 0.027 -inch microcatheter and typically use a $6 \mathrm{~F}$ or $7 \mathrm{~F}$ guide catheter; however, $5 \mathrm{~F}$ intermediate catheters are also used. ${ }^{11,15}$

The first-generation PED is the most studied device to date. The 2 most prominent prospective studies, the Pipeline for the Intracranial Treatment of Aneurysms (PITA) and Pipeline for Uncoilable or Failed Aneurysms (PUFS) trials (registration stud- 
ies for Europe and United States, respectively), showed occlusion rates of approximately $75 \%-95 \%$ at 6 months to 5 years in patients with unruptured wide-neck aneurysms of the ICA (On-line Table 2). Patients in the PUFS study also had excellent neuroophthalmologic outcomes at 6 months. Morbidity (in terms of permanent neurologic disability) and mortality were low, at approximately $0 \%-3 \%$ each. ${ }^{16-19}$ A prospective observational study (Aneurysm Study of Pipeline in an Observational Registry [ASPIRe]) confirmed that the PED in a heterogeneous patient population with unruptured large/giant aneurysms of the ICA was safe, with low rates of neurologic morbidity and mortality (On-line Table 2). ${ }^{20}$

These outcomes were consistent with a large, retrospective, safety series (International Retrospective Study of Pipeline Embolization Device [IntrePED]). ${ }^{21}$ In this series, further analysis showed that neurologic morbidity and mortality increased with age (though only the former was statistically marked), but both were still acceptably low in elderly patients. ${ }^{22}$ Of 793 patients, 20 $(2.5 \%)$ had intraparenchymal hemorrhage (unrelated to the index aneurysm rupture); risk factors included treatment of ruptured aneurysms and use of multiple devices. ${ }^{23}$ The fusiform aneurysm was the only variable independently associated with postoperative stroke. $^{24}$

The PED is being used increasingly for off-label indications. For posterior circulation aneurysms, subgroup analysis from the IntrePED safety series showed neurologic morbidity and mortality comparable with reported rates after clipping or coiling. Nevertheless, rates of morbidity and mortality after flow-diversion treatment were higher among posterior circulation (16.5\%) compared with anterior circulation (5\%-9\%) lesions. ${ }^{25}$ In this and other series, flow diversion in the posterior circulation has been shown to be associated with ischemic complications related to perforator infarcts, which are not negligible. ${ }^{26,27}$ Use in fusiform aneurysms (especially basilar) or use of $\geq 3$ devices was associated with a higher risk. ${ }^{25}$ Occlusion rates for posterior circulation aneurysms have been reported separately at approximately $80 \%$, within the range for anterior circulation aneurysms (On-line Table 2). ${ }^{28}$ Regarding off-label use for MCA aneurysms, a 2017 meta-analysis suggested that the treatment is feasible but should be considered as an alternative given a non-negligible rate of complications. $^{29,30}$ The same group responsible for this meta-analysis also used a similar technique to analyze multiple small retrospective series of acutely ruptured aneurysms in 2018 and reported high rates of long-term occlusion but with a complication rate of $18 \%$ in the anterior and $27 \%$ in the posterior circulation. ${ }^{31}$

Last, a 2018 meta-analysis of distal aneurysms also suggested reasonably high rates of occlusion (70\%) with marked complication rates $(20 \%) .^{32}$ Limited studies of dissecting and fusiform aneurysms demonstrate comparable outcomes to vessel sacrifice in the long term, with potentially greater short-term complications. ${ }^{33}$ The PED has been shown to be safe and effective for many off-label uses, though these require ongoing evaluation. The forthcoming Prospective Study on Embolization of Intracranial Aneurysms with Pipeline Embolization Device (PREMIER) trial data suggest that small aneurysms may be treated safely in an off-label fashion in many situations as well. 3D rotational angiography studies of virtual stent placement have shown utility in simulating vessel geometry and, in particular, show that delivery manipulation and vessel radius have a marked effect on PED apposition. ${ }^{34}$ In the context of braided stents, local porosity and filament position have been modeled with conebeam CT, which may provide critical information to the diagnostic and interventional neuroradiologist about deployment prediction. ${ }^{35}$

Outcome data for the Pipeline Flex are still limited, but initial results support its safety and short-term efficacy. ${ }^{36}$ High rates of occlusion with low rates of short- and long-term disability have been reported from several selected small studies, as follows: in 10 patients with 11 anterior saccular aneurysms, ${ }^{12}$ in 42 patients with 44 predominantly anterior saccular aneurysms, ${ }^{37}$ and in $30 \mathrm{pa}-$ tients with 30 predominantly anterior saccular aneurysms. ${ }^{38}$ The Pipeline Flex device has been shown to reduce total procedure and fluoroscopy times and the rate of deployment failure compared with the original PED. ${ }^{39}$ It remains to be seen whether the design modifications of the Pipeline Flex will translate into improved long-term outcomes and/or use of this technology in a wider range of indications. Regarding the Pipeline Shield, a prospective singlearm study evaluating its use in 50 patients with 50 unruptured, predominantly saccular internal carotid aneurysms achieved complete wall apposition in $96 \%$ of cases, with no major strokes or neurologic mortality during 30 days postprocedure. ${ }^{14}$

The next conventional braided mesh device to debut was the original Silk device, also a flexible mesh stent made from 48 braided nitinol and 4 platinum microfilaments, which was approved in Europe in 2008 - the first such device to enter clinical use for intracranial aneurysm management. ${ }^{40,41}$ The platinum strands with 2 flared ends act as radiopaque markers. A newgeneration Silk + device has flared ends, lower porosity, higher radial force, greater slide capacity, an extrasupple and shorter $(9 \mathrm{~mm}$ ) distal radiopaque tip, and 8 platinum markers (Fig 2). ${ }^{42}$ Like its predecessor, the Silk + device requires a smaller delivery microcatheter than other similar endovascular devices, 0.023 inches, though like others, it uses a $6 \mathrm{~F}$ or $7 \mathrm{~F}$ guide catheter. ${ }^{4}$ Tapered options are available for use in irregular anatomies.

Of note is the observation from in vitro modeling studies that the MCR for the original Silk device had been reported as only $21 \%$ when stent and vessel were matched in a straight model segment versus a nominal MCR of 40\%-55\% (On-line Table 1). ${ }^{43}$ The MCR was decreased at oversizing (for straight segments and on the convexity of a curved segment) and for matched stent and segment diameters on the concavity because of dynamic wire repositioning. These results are clinically relevant because of the requirement to maximize and minimize the MCR across the aneurysm ostium and branch vessel orifice, respectively. The original device was withdrawn from the market.

Most outcome data were generated from small studies of the original Silk device, which was intended for use in complex intracranial aneurysms. This feature may partly explain why occlusion rates were as low as approximately $50 \%$ at 4 months' follow-up, benchmarking poorly compared with PED data (On-line Table 2). ${ }^{44-49}$ Morbidity and mortality were also higher than for PED studies, consistent with more challenging indications, including a high proportion of patients with fusiform aneurysms in some 

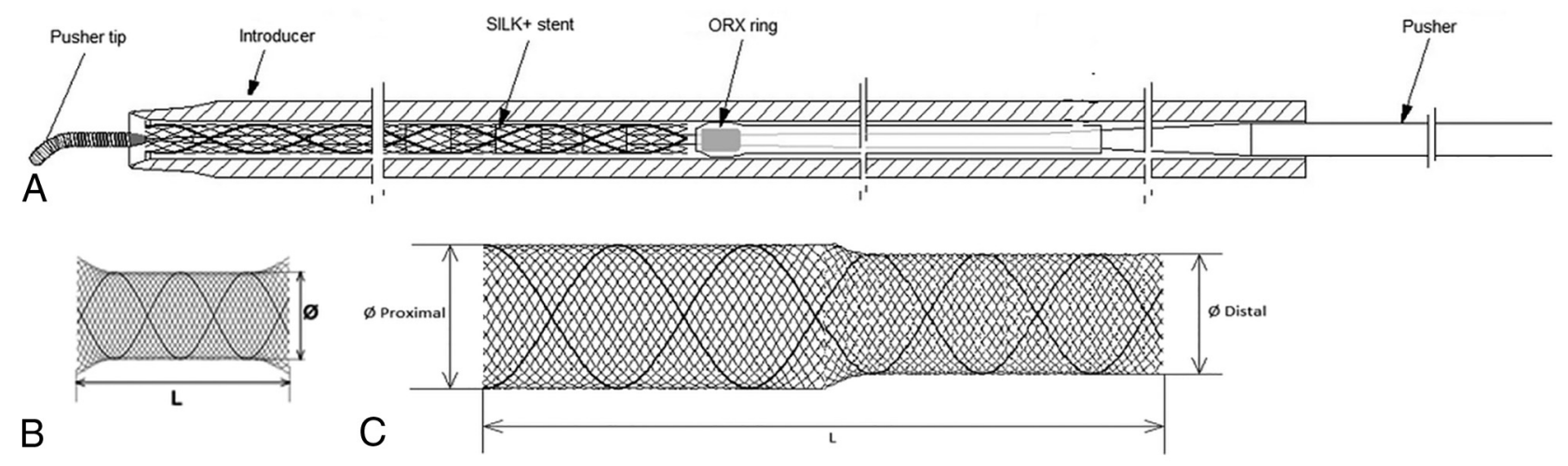

B

C

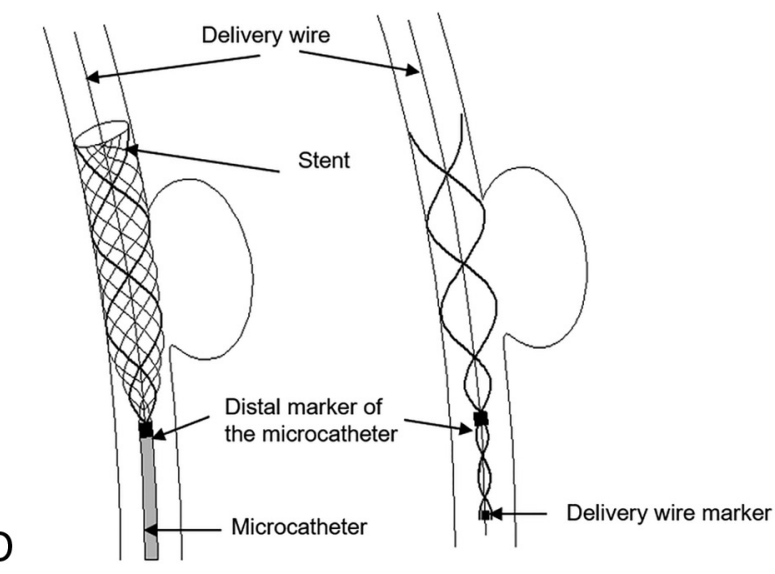

FIG 2. $A$, Silk + assembly schematic with the placement system and pusher. The mono- $(B)$ and bidiameter $(C)$ Silk + model as well as illustration of the position and deployment of the stent and radiopaque markers $(D)$. Courtesy of Balt Extrusion, Montmorency, France.

studies. For studies that included patients with presentations similar to those in the initial PED studies (ie, unruptured large- or wide-neck lesions of the petrous to the superior hypophyseal ICA), the Silk seems to benchmark well compared with the PED, achieving occlusion rates approaching 90\% at approximately 18 months' follow-up, though complication rates were still higher, suggesting that the device had shortcomings irrespective of aneurysm complexity. ${ }^{49}$ One study with a very challenging patient population, however, reported 1-year occlusion rates of $84 \%$, alongside morbidity and mortality comparable with that in the IntrePED trial. ${ }^{21,48}$

Despite being first to market among flow-diverting stents, the Silk has a relatively sparse evidence base compared with the PED, and caution must be exercised when making comparisons among studies because variables differ. The Silk has been studied with computational flow dynamics showing predictable decreases in wall shear stress and intra-aneurysmal flow velocities. Flow-pattern change is less consistently demonstrated, and this feature may relate to porosity. ${ }^{50}$ In PED studies, it has been seen that when particle imaging velocimetry shows marked reductions, computational flow dynamics velocity fields do not always predictably change in a linear manner to particle imaging velocimetry, which may be relevant in transition hemodynamic regimes. ${ }^{51,52}$ Mean aneurysmal flow amplitude assessment of the Silk and PED using DSA has predicted thrombosis at certain thresholds for these braided devices. ${ }^{53}$

Regarding the Silk+, evidence is lacking. One small retrospective study of 58 patients with 70 aneurysms (including patients with prior or current $\mathrm{SAH}$ ) compared outcomes for patients who received the original Silk device with those treated with Silk+ during nearly 1 year. Most patients did not undergo concomitant coiling. Delayed thromboembolic complications were seen in $10.6 \%$ of patients, and permanent neurologic morbidity, in 5.5\%, all cases occurring in patients treated with the first-generation device; there was no procedure-related mortality. The overall occlusion rate across both devices was $73 \%$, and there were no recanalizations. ${ }^{44}$ It can be inferred, albeit tentatively, that the secondgeneration Silk + is safer than its predecessor, but more studies and data are needed to make definitive conclusions.

\section{Dual-Porosity and Fixed-Porosity}

The FRED is a self-expanding nickel titanium paired stent comprising integrated dual-layer coverage provided by a low-porosity inner mesh of higher pore attenuation (48 nitinol wires) and an outer stent with high porosity (16 nitinol wires with 4 interwoven marker strands), as well as proximal and distal markers. The dual layer is restricted to the midsection, covering approximately $80 \%$ of the length of the device with the aim of increasing coverage across the aneurysm ostium. It can be deployed and partially resheathed by a single operator using a 0.027 -inch microcatheter (On-line Table 1). ${ }^{11,54,55}$ The FRED, Silk, and PED have been studied with 4D flow MR imaging for the detection of intrastent streamline changes and velocity reductions. Regarding animal studies, the FRED is the most comprehensively tested in complex canine aneurysm models as opposed to rabbits. This may be im- 


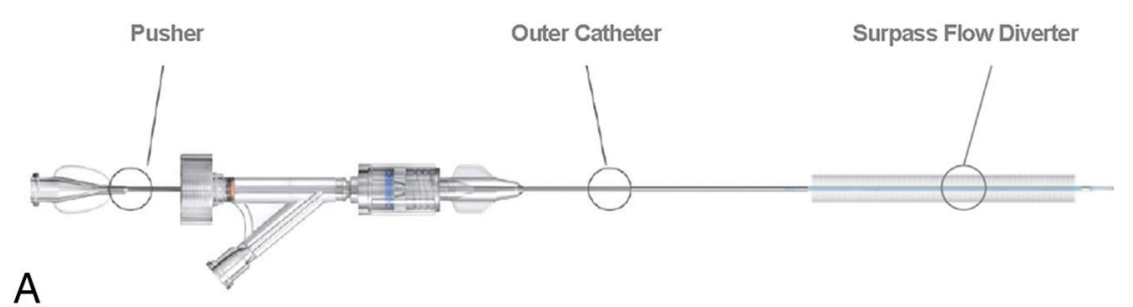

A

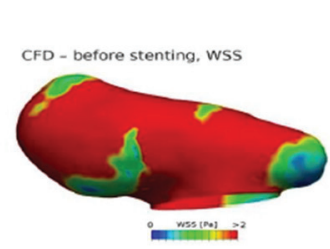

48 Wire

Braid

72 Wire

Braid

(Surpass)

$\mathrm{B}$

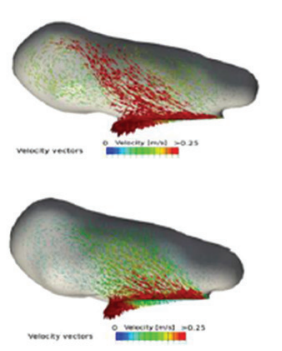

- Porosity: Ratio of metal-free surface area in a stented vessel

- Pore Density: Number of pores per unit surface area (holes $/ \mathrm{mm}^{2}$ )

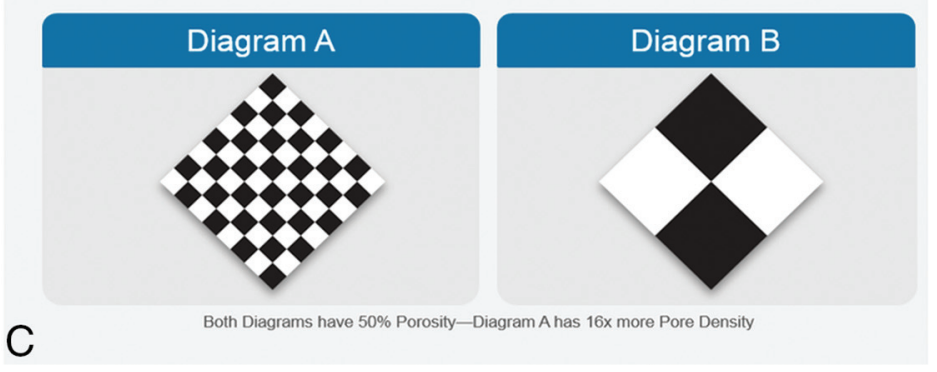

FIG 3. $A$, Surpass deployment system schematic. $B$, By increasing the number of wires while decreasing the size of the wire, the Surpass stent hypothetically creates more flow diversion while maintaining a consistent porosity. C, Computational flow dynamics shows the relationship between porosity and pore attenuation and how porosity may be maintained while increasing pore attenuation. Courtesy of Stryker Neurovascular, Kalamazoo, MI.

portant because wide-neck and bifurcation aneurysms have been tested as well as porosity variations at anatomic tortuosities. ${ }^{56}$

Data from studies evaluating the FRED are still relatively sparse, with the European Multicenter Study for the Evaluation of a Dual-Layer Flow-Diverting Stent for Treatment of Wide-Neck Intracranial Aneurysms study representing the only large multicenter study (On-line Table 2). ${ }^{57}$ In several small studies, including studies that included patients with complex aneurysm morphologies, the FRED appeared to benchmark similar to the PED and better than the Silk (especially in terms of safety). ${ }^{40,55,58-60}$ As mentioned previously, however, cross-study comparisons must be interpreted with caution. The FRED has been approved and has been available in Europe for several years and is in late-stage evaluation in a Phase III multicenter US trial in patients with wide-neck aneurysms of the ICA (Pivotal Study of the FRED Stent System in the Treatment of Intracranial Aneurysms; NCT01801007). The FRED offers higher radial force and, in our experience, excellent performance in paraclinoid aneurysms. The device may twist, and we have noted occasional unexplained acute or subacute thrombosis unrelated to antiaggregation activity. A smaller form factor, Fred Jr, may be used in bifurcation aneurysms and in aneurysms on small-sized vessels.

The Surpass Streamline flow diverter is a cobalt-chromium alloy stent with 12 platinum wires to aid radiopacity. The Surpass stent was designed to optimize the flow-diversion profile, with

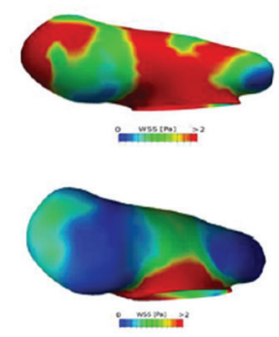

approximately $70 \%$ porosity and a pore attenuation of at least 20 pores $/ \mathrm{mm}^{2}$. The design operates on the premise that flow diversion is related not just to the metal-to-artery ratio but also to the number of pores (Fig 3). To maintain a consistent pore attenuation of $>20$ pores $/ \mathrm{mm}^{2}$, the Surpass has more wires than the other flow diverters and has a different number of metal struts, ranging from 48 in the 2-mm-diameter devices to 96 for $5 \mathrm{~mm}^{54}$

The other unique attribute of the Surpass is that it is an over-the-wire system, with the stent preloaded at the tip of the catheter. The system was designed this way to maintain wire access in case the stent needed to be re-crossed postdeployment, an advantage the Pipeline Flex also offers. The other benefit is the stability an over-the-wire system provides during stent deployment, even for long lengths. The downside is that the system is larger in nature, with a delivery microcatheter with a 0.040 -inch inner diameter. ${ }^{61}$ Clinical data are limited but outcomes are predictable. For less challenging indications, occlusion rates and complications were favorable, while for more high-risk presentations, occlusion rates were lower and mortality was high (On-line Table 2). ${ }^{62,63}$ The Surpass is under evaluation for FDA approval in the Surpass Intracranial Aneurysm Embolization System Pivotal Trial to Treat Large or Giant Wide Neck Aneurysms (SCENT; NCT01716117), which reached primary end point completion in July 2017. The Surpass Flow Diverter for Intracranial Aneurysms (SURMOUNT registry; https://www. centerwatch.com/clinical-trials/listings/66634/cerebral-aneurysmsurpass-flow-diverter-intracranial/), a prospective multicenter postmarket surveillance study in Europe, is ongoing. This selfexpandable stent mounted into the delivery catheter comprises up to 96 wires, thus providing more coverage. The Surpass is comparatively stiff and may be best navigated over a 5F distal access catheter across the aneurysm neck.

\section{Next-Generation Nitinol Devices}

The Tubridge is a braided, self-expanding device with flared ends that is approved in China. To minimize the shortening rate after full opening, large versions (diameter, $\geq 3.5 \mathrm{~mm}$ ) comprise a braid of 62 nickel-titanium microfilaments and 2 platinum-iridium microfilaments, while small versions (diameter, $<3.5 \mathrm{~mm}$ ) comprise 46 nitinol and 2 platinum-iridium microfilaments. The MCR is comparable with that in the PED and with the limited outcome data, with the most marked being the Parent Artery Reconstruction for Large or Giant Cerebral Aneurysms Using the Tubridge Flow Diverter (PARAT) trial of large and giant aneurysms (On-line 


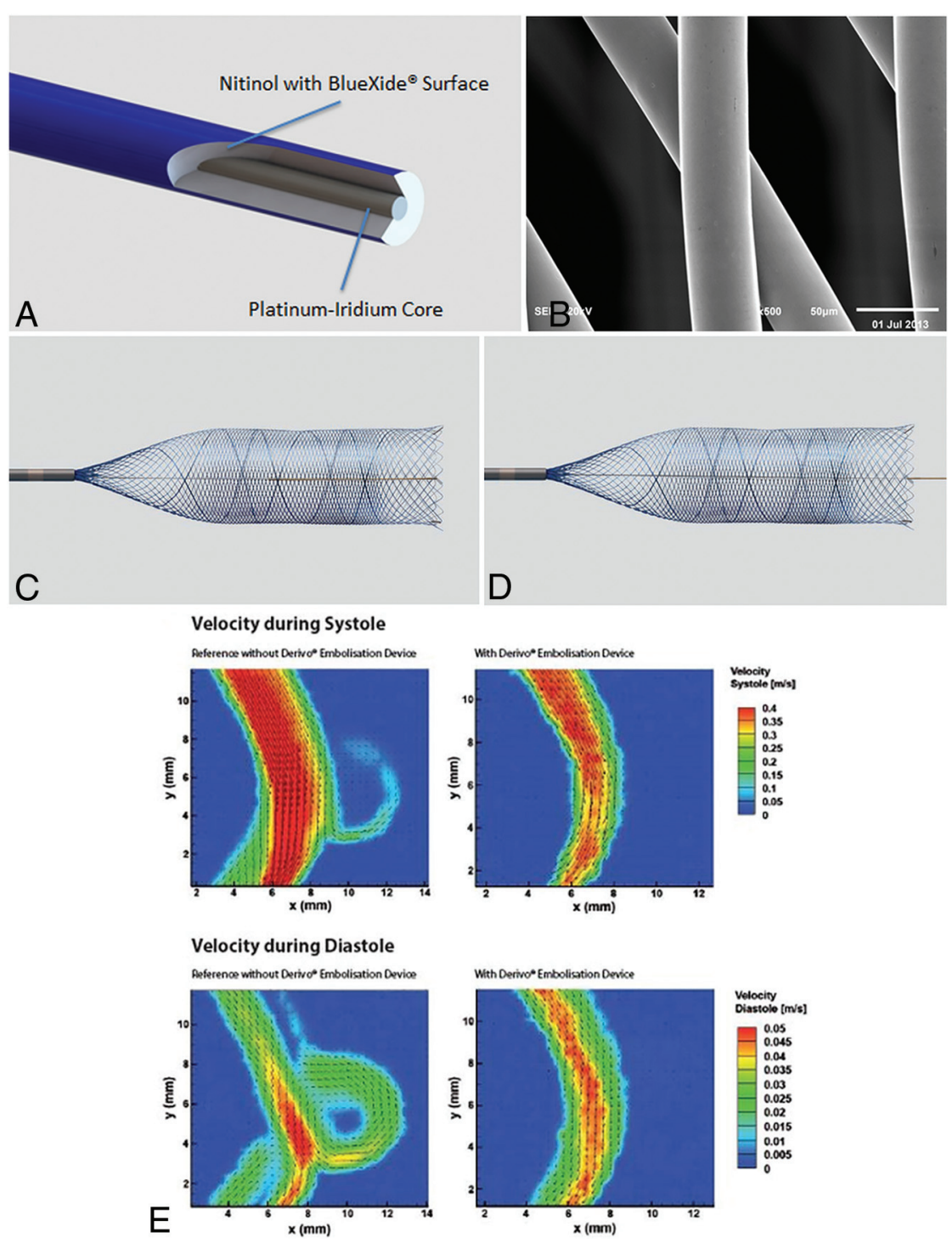

FIG 4. $A$, Unconstrainted view of the Derivo Embolization Device $(A)$ and magnified view of the BlueXide $(B)$ surface of the Derivo Embolization Device acquired with a scanning electron microscope. The Derivo has closed, flared ends and may be used without a tip for increased flexibility $(C)$ and with a tip for distal support and retention after release $(D)$. E, Particle image velocimetry demonstrates effective flow diversion in an in vitro setting. Courtesy of Department of Cardiovascular Engineering, RWTH Aachen University in Aachen, North Rhine-Westphalia, Germany.

ence, the device is useful for supraclinoid aneurysms, and its latest iteration is similar in characteristics to the $\mathrm{p} 64$.

Finally, the p64 device is a flexible, meshlike tube of 64 interwoven nitinol microfilaments grouped into 8 proximal radiopaque bundle markers, deployed using an 0.027-inch microcatheter. The p64 is completely recoverable- even after complete deployment-because of its controlled mechanical detachment (On-line Table 1). ${ }^{4,54}$ Data are limited, but several retrospective studies have shown midterm occlusion rates of at least $85 \%$ with low morbidity/mortality (On-line Table 2). ${ }^{11,69,70}$ As with all new devices, there will be a learning curve to consider. For noncontrolled descriptive studies, there is the potential for publication bias with this and all subsequent devices discussed herein. In our experience, this nitinol device is best used on small-neck or smaller overall aneurysms. The p64 does not have a distal wire for support, which may be an issue for telescoping or overly wide-neck aneurysms. The device is fully recoverable after full deployment; however, some proximal opening issues have occurred.

\section{Bifurcation Hybrids}

The second-generation eCLIPs is a novel, self-expanding, nitinol, non-circumferential, hybrid device with flow diverter properties, specifically designed for bifurcation aneurysms (Fig 5 and On-line Table 1). It has platinum radiopaque markers and comprises two discrete sections: an anchor segment designed to conform to vessel walls beside

Tables 1 and 2). ${ }^{64,65}$ The Tubridge, Surpass, FRED, Silk, and PED have been tested in rabbit elastase models with acceptable occlusion rates. While this model is commonly used and favored, it is not universally standardized. ${ }^{66}$

By comparison, the Derivo comprises 48 braiding nitinol wires with a radiopaque platinum core (Fig 4), which has undergone laboratory testing including particle image velocimetry. The device has flared ends with the goal of improved apposition. Only very preliminary data are available from 1 small study, which showed improving occlusion rates with time and no obvious safety flags (On-line Table 2). ${ }^{67}$ The Derivo, Silk, and PED have undergone same-parameter particle imaging velocimetry testing showing that for all 3, the inflow-outflow is reversed from the proximal-to-distal aneurysm neck, after which a low-flow eddy predominates. There was a slightly higher susceptibility to inflow waveform/transient backflow with the Silk only. ${ }^{68}$ In our experi- the aneurysm ostium, and a leaf segment with flow-diverter properties which has moveable ribs to allow trans-device coil delivery. Data from numerous challenging presentations are shown in Online Table $2 .^{71}$ eCLIPs is potentially unique as it is the only device to date which shows endothelialization as a bifurcation hybrid device. The European eCLIPs Safety, Feasibility an Efficacy Study (EESIS) is a prospective, multicenter cohort/registry study which is ongoing.

Like the eCLIPs, the Sphere (Minimally Invasive New Technologies [MINT]; Weill Cornell Medicine, New York, New York) was designed specifically for bifurcation aneurysms. It is constructed from a single loop of nitinol wire and reduces aneurysm inflow via a high-attenuation, patterned, elliptic surface that partially occludes the ostium (Fig 6 and On-line Table 1). The device is secured by multiple open hoops deployed in the parent vessel distal to the aneurysm, leaving daughter vessels unobstructed 


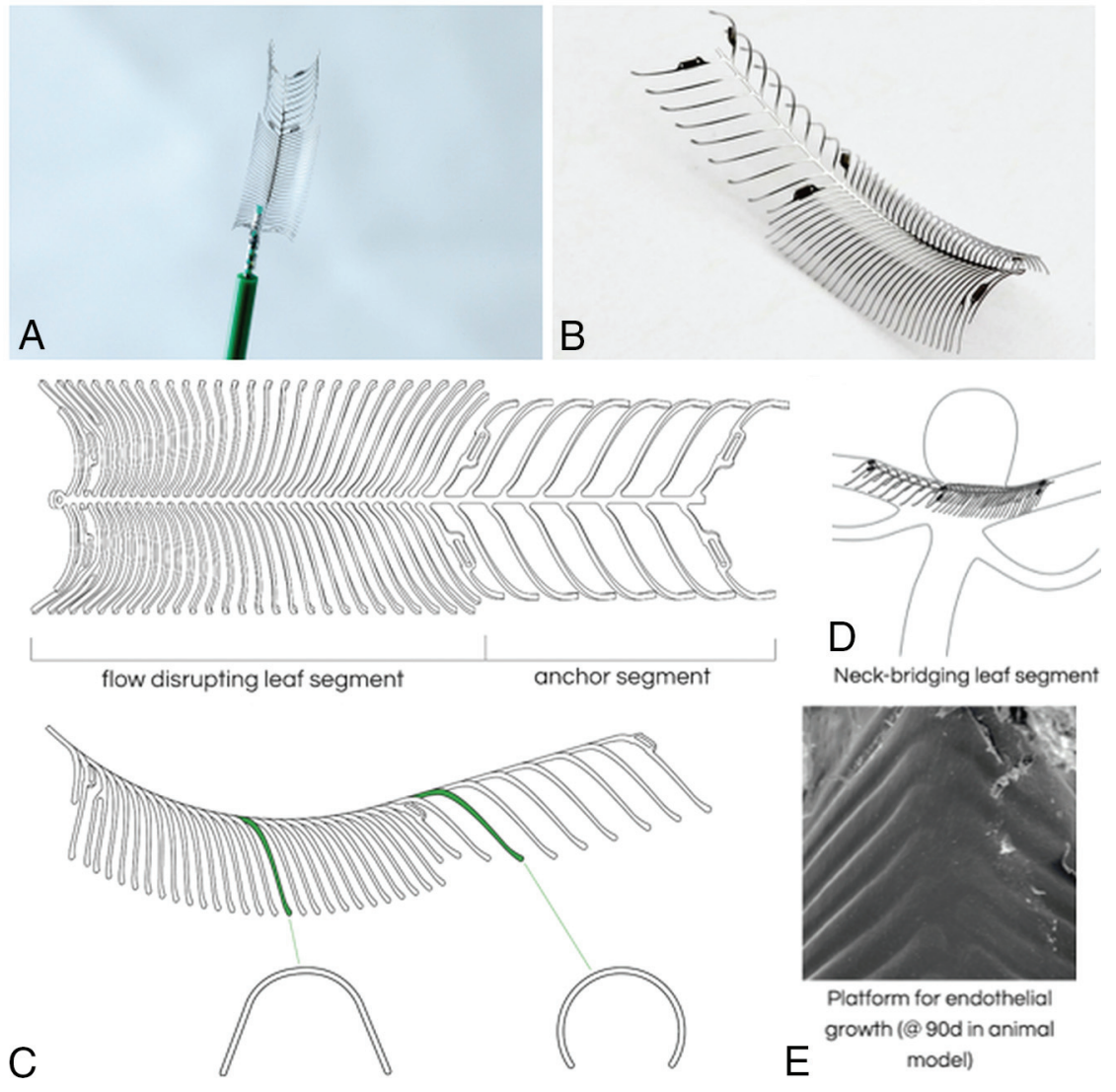

FIG 5. The bifurcation device eCLIPs $(A)$ with a self-aligning spine rib design $(B)$ having flowdisrupting and anchor segments $(C)$ to enable repositioning but no migration/shortening following deployment. $D$, Noncircumferential morphology designed for wall apposition, which does not reside in the parent vessel or impede side branches. $E$, Scanning electron micrograph demonstrates neoendothelialization in vivo. Courtesy of the CV Path Institute, Gaithersburg, Maryland. while not protruding into the delicate aneurysm dome. As yet, no clinical data are available. $^{72}$

\section{CONCLUSIONS}

For many types of aneurysms, flow diversion has rapidly become the treatment of choice because cure rates are high and complications rates are reasonably low. Unlike traditional stents, which require a high radial opening force, flow-diverting stents are designed to have a low radial opening force to facilitate navigability. Moreover, flow-diverting stents require greater metal coverage and decreased porosity while maintaining pore attenuation; this has been achieved using a braided metallic design for many devices. Early preclinical experiments suggested that the optimal porosity for aneurysm occlusion is $70 \%$, but this may vary in practice according to vessel configuration and device sizing. Oversizing generally should be avoided, and the number of devices used per aneurysm should be minimized to reduce the risk of complications. There are too few data to make definitive recommendations on the choice of a device for bifurcation or ruptured aneurysms.

There are minimal data on the PED Flex alone; however, given that the device is similar to its forerunner, we may

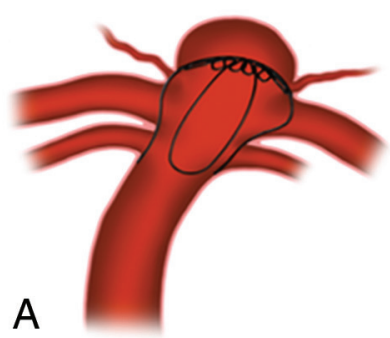

$56 \%$ Peak flow reduction

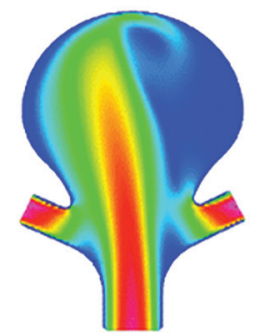

C Flow without Sphere
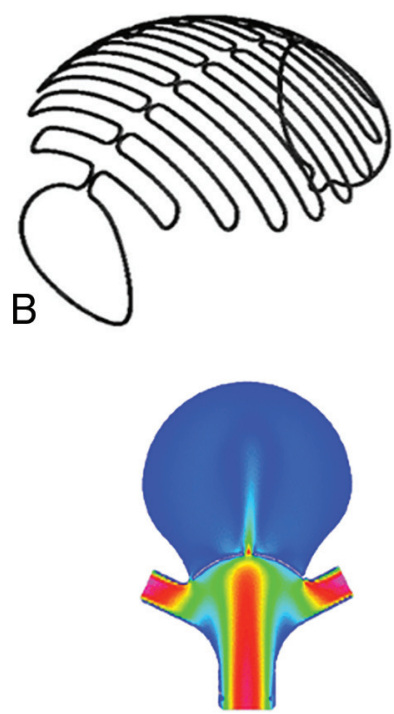

Flow with Sphere

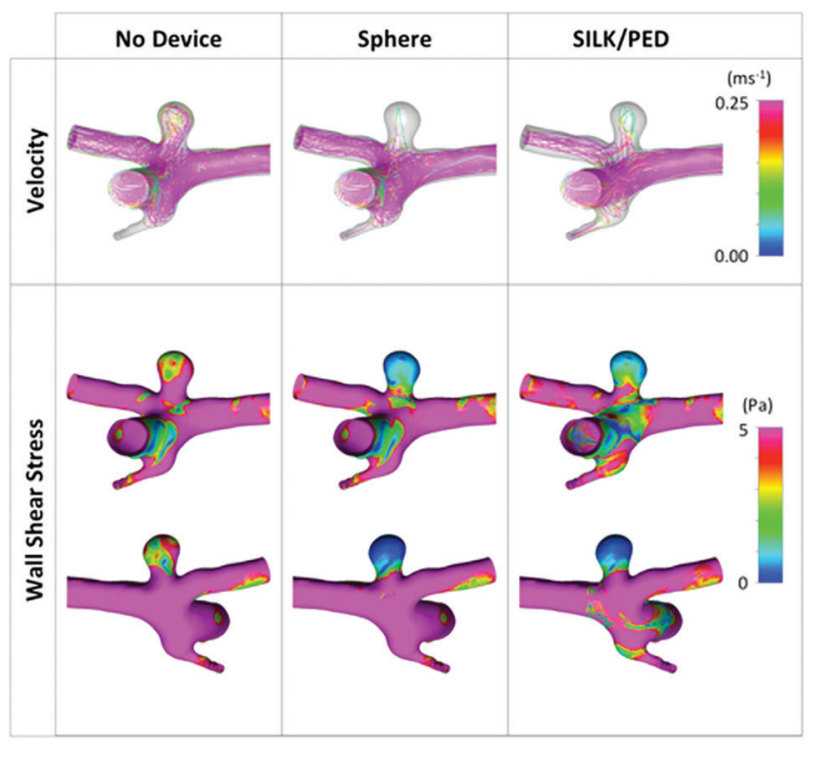

FIG 6. $A$, Sphere device with a high-attenuation nitinol face within a bifurcation aneurysm with thin-wire anchor legs $(B)$ designed to direct flow downstream. C, Computational flow dynamics study demonstrates decreased peak flow reduction to the aneurysm sac as well as velocity and wall shear stress $(D)$, which is superior in Sphere compared to conventional endoluminal devices in some aneurysm/branch vessel morphologies in animal models. Courtesy of the Weill Cornell School of Medicine, New York, New York. 
reasonably expect at least equivalent outcomes, possibly with improved procedural performance. Two devices could be approved in the United States within the next 2 years (the FRED and Surpass). Limited data likely reflect a learning curve for some devices, and outcomes should improve with experience. Further studies are needed to relate technical specifications to device performance and outcomes and hence optimize usage, particularly for the most challenging aneurysm presentations.

Disclosures: Vitor Mendes Pereira-RELATED: Consulting Fee or Honorarium: Medtronic, Stryker, Balt, Cerenovous, Comments: participating in studies or proctoring.* Ajith J. Thomas—RELATED: Fees for Participation in Review Activities Such as Data Monitoring Boards, Statistical Analysis, Endpoint Committees, and the Like: Stryker, Comments: Data Safety Monitoring Board for the SCENT trial*; UNRELATED: Expert Testimony: CRICO, Comments: brain aneurysm treatment. *Money paid to the institution.

\section{REFERENCES}

1. Walcott BP, Stapleton CJ, Choudhri O, et al. Flow diversion for the treatment of intracranial aneurysms. JAMA Neurol 2016;73: 1002-08 CrossRef Medline

2. Al-Mufti F, Amuluru K, Gandhi CD, et al. Flow diversion for intracranial aneurysm management: a new standard of care. Neurotherapeutics 2016;13:582-89 CrossRef Medline

3. Thompson BG, Brown RD Jr, Amin-Hanjani S, et al; American Heart Association Stroke Council, Council on Cardiovascular and Stroke Nursing, and Council on Epidemiology and Prevention, American Heart Association, American Stroke Association, Guidelines for the Management of Patients with Unruptured Intracranial Aneurysms: a Guideline for Healthcare Professionals From the American Heart Association/American Stroke Association. Stroke 2015;46:2368-400 CrossRef Medline

4. Briganti F, Leone G, Cirillo L, et al. Postprocedural, midterm, and long-term results of cerebral aneurysms treated with flow-diverter devices: 7-year experience at a single center. Neurosurg Focus 2017; 42:E3 CrossRef Medline

5. Sadasivan C, Cesar L, Seong J, et al. An original flow diversion device for the treatment of intracranial aneurysms: evaluation in the rabbit elastase-induced model. Stroke 2009;40:952-58 CrossRef Medline

6. Shapiro M, Raz E, Becske T, et al. Variable porosity of the Pipeline embolization device in straight and curved vessels: a guide for optimal deployment strategy. AJNR Am J Neuroradiol 2014;35:727-33 CrossRef Medline

7. Jou LD, Chintalapani G, Mawad ME. Metal coverage ratio of Pipeline embolization device for treatment of unruptured aneurysms: reality check. Interv Neuroradiol 2016;22:42-48 CrossRef Medline

8. Chalouhi N, Tjoumakaris S, Phillips JL, et al. A single Pipeline embolization device is sufficient for treatment of intracranial aneurysms. AJNR Am J Neuroradiol 2014;35:1562-66 CrossRef Medline

9. Moshayedi H, Omofoye OA, Yap E, et al. Factors affecting the obliteration rate of intracranial aneurysms treated with a single Pipeline embolization device. World Neurosurg 2017;104:205-12 CrossRef Medline

10. Iosif C, Mounayer C, Yavuz K, et al. Middle cerebral artery bifurcation aneurysms treated by extrasaccular flow diverters: midterm angiographic evolution and clinical outcome. AJNR Am J Neuroradiol 2017;38:3 CrossRef Medline

11. Briganti F, Leone G, Ugga L, et al. Mid-term and long-term follow-up of intracranial aneurysms treated by the p64 Flow Modulation Device: a multicenter experience. J Neurointerv Surg 2017;9: 70-76 CrossRef Medline

12. Pereira VM, Kelly M, Vega P, et al. New Pipeline Flex device: initial experience and technical nuances. J Neurointerv Surg 2015;7:920-25 CrossRef Medline

13. Martinez-Galdámez M, Gil A, Caniego JL, et al. Preliminary experience with the Pipeline Flex Embolization Device: technical note. J Neurointerv Surg 2015;7:748-51 CrossRef Medline
14. Martinez-Galdámez M, Lamin SM, Lagios KG, et al. Periprocedural outcomes and early safety with the use of the Pipeline Flex Embolization Device with Shield Technology for unruptured intracranial aneurysms: preliminary results from a prospective clinical study. J Neurointerv Surg 2017;9:772-76 CrossRef Medline

15. Hanel RA, Aguilar-Salinas P, Brasiliense LB, et al. First US experience with Pipeline Flex with Shield Technology using aspirin as antiplatelet monotherapy. BMJ Case Rep 2017;2017 CrossRef Medline

16. Nelson PK, Lylyk P, Szikora I, et al. The Pipeline embolization device for the intracranial treatment of aneurysms trial. AJNR Am J Neuroradiol 2011;32:34-40 CrossRef Medline

17. Becske $T$, Brinjikji W, Potts $M B$, et al. Long-term clinical and angiographic outcomes following Pipeline Embolization Device treatment of complex internal carotid artery aneurysms: five-year results of the Pipeline for uncoilable or failed aneurysms trial. Neurosurgery 2017;80:40-48 CrossRef Medline

18. Becske T, Kallmes DF, Saatci I, et al. Pipeline for uncoilable or failed aneurysms: results from a multicenter clinical trial. Radiology 2013; 267:858-68 CrossRef Medline

19. Becske T, Potts MB, Shapiro M, et al. Pipeline for uncoilable or failed aneurysms: 3-year follow-up results. J Neurosurg 2017;127:81-88 CrossRef Medline

20. Kallmes DF, Brinjikji W, Boccardi E, et al. Aneurysm Study of Pipeline in an Observational Registry (ASPIRe). Interv Neurol 2016;5: 89-99 CrossRef Medline

21. Kallmes DF, Hanel R, Lopes D, et al. International retrospective study of the Pipeline Embolization Device: a multicenter aneurysm treatment study. AJNR Am J Neuroradiol 2015;36:108-15 CrossRef Medline

22. Brinjikji W, Lanzino G, Cloft HJ, et al. Risk factors for ischemic complications following Pipeline Embolization Device treatment of intracranial aneurysms: results from the IntrePED Study. AJNR Am J Neuroradiol 2016;37:1673-78 CrossRef Medline

23. Brinjikji W, Lanzino G, Cloft HJ, et al. Risk factors for hemorrhagic complications following Pipeline Embolization Device treatment of intracranial aneurysms: results from the international retrospective study of the Pipeline Embolization Device. AJNR Am J Neuroradiol 2015;36:2308-13 CrossRef Medline

24. Brinjikji W, Kallmes DF, Cloft HJ, et al. Age-related outcomes following intracranial aneurysm treatment with the Pipeline Embolization Device: a subgroup analysis of the IntrePED registry. $J \mathrm{Neu}$ rosurg 2016;124:1726-30 CrossRef Medline

25. Lopes DK, Jang DK, Cekirge S, et al. Morbidity and mortality in patients with posterior circulation aneurysms treated with the Pipeline Embolization Device: a subgroup analysis of the international retrospective study of the Pipeline Embolization device. Neurosurgery 2018;83:488-500 CrossRef Medline

26. Liang F, Zhang Y, Guo F, et al. Use of Pipeline Embolization Device for posterior circulation aneurysms: single-center experiences with comparison with anterior circulation aneurysms. World Neurosurg 2018;112:e683-90 CrossRef Medline

27. Wang CB, Shi WW, Zhang GX, et al. Flow diverter treatment of posterior circulation aneurysms: a meta-analysis. Neuroradiology 2016;58:391-400 CrossRef Medline

28. Dmytriw AA, Adeeb N, Kumar A, et al. Flow diversion for the treatment of basilar apex aneurysms. Neurosurgery 2018;83:1298-1305 CrossRef Medline

29. Patel PD, Chalouhi N, Atallah E, et al. Off-label uses of the Pipeline embolization device: a review of the literature. Neurosurg Focus 2017;42:E4 CrossRef Medline

30. Cagnazzo F, Mantilla D, Lefevre PH, et al. Treatment of middle cerebral artery aneurysms with flow-diverter stents: a systematic review and meta-analysis. AJNR Am J Neuroradiol 2017;38:2289-94 CrossRef Medline

31. Cagnazzo F, di Carlo DT, Cappucci M, et al. Acutely ruptured intracranial aneurysms treated with flow-diverter stents: a systematic review and meta-analysis. AJNR Am J Neuroradiol 2018;39:1669-75 CrossRef Medline 
32. Yan Y, Zhu D, Tang H, et al. Safety and efficacy of flow diverter treatment for aneurysm in small cerebral vessels: a systematic review and meta-analysis. World Neurosurg 2018;115:54-64 CrossRef Medline

33. Fang YB, Lin A, Kostynskyy A, et al. Endovascular treatment of intracranial vertebrobasilar artery dissecting aneurysms: parent artery occlusion versus flow diverter. Eur J Radiol 2018;99:68-75 CrossRef Medline

34. Bouillot $\mathrm{P}$, Brina $\mathrm{O}$, Yilmaz $\mathrm{H}$, et al. Virtual-versus-real implantation of flow diverters: clinical potential and influence of vascular geometry. AJNR Am J Neuroradiol 2016;37:2079-86 CrossRef Medline

35. Bouillot P, Brina O, Ouared R, et al. Geometrical deployment for braided stent. Med Image Anal 2016;30:85-94 CrossRef Medline

36. Aguilar-Salinas P, Brasiliense LB, Gonsales D, et al. Evaluation of Pipeline Flex delivery system for the treatment of unruptured aneurysms. Expert Rev Med Device 2016;13:885-97 CrossRef Medline

37. Colby GP, Lin LM, Caplan JM, et al. Immediate procedural outcomes in $\mathbf{4 4}$ consecutive Pipeline Flex cases: the first North American single-center series. J Neurointerv Surg 2016;8:702-09 CrossRef Medline

38. Martinez-Galdámez M, Pérez S, Vega A, et al. Endovascular treatment of intracranial aneurysms using the Pipeline Flex embolization device: a case series of $\mathbf{3 0}$ consecutive patients. J Neurointerv Surg 2016;8:396-401 CrossRef Medline

39. Le EJ, Miller T, Serulle Y, et al. Use of Pipeline Flex is associated with reduced fluoroscopy time, procedure time, and technical failure compared with the first-generation Pipeline embolization device. J Neurointerv Surg 2016 Mar 9. [Epub ahead of print] CrossRef Medline

40. Briganti F, Leone G, Ugga L, et al. Safety and efficacy of flow redirection endoluminal device (FRED) in the treatment of cerebral aneurysms: a single center experience. Acta Neurochir (Wien) 2016; 158:1745-55 CrossRef Medline

41. Murthy SB, Shah S, Shastri A, et al. The Silk flow diverter in the treatment of intracranial aneurysms. J Clin Neurosci 2014;21: 203-06 CrossRef Medline

42. Alghamdi F, Morais R, Scillia P, et al. The Silk flow-diverter stent for endovascular treatment of intracranial aneurysms. Expert Rev Med Devices 2015;12:753-62 CrossRef Medline

43. Aurboonyawat T, Blanc R, Schmidt $\mathrm{P}$, et al. An in vitro study of Silk stent morphology. Neuroradiology 2011;53:659-67 CrossRef Medline

44. Lubicz B, Collignon L, Raphaeli G, et al. Flow-diverter stent for the endovascular treatment of intracranial aneurysms: a prospective study in 29 patients with 34 aneurysms. Stroke 2010;41:2247-53 CrossRef Medline

45. Byrne JV, Beltechi R, Yarnold JA, et al. Early experience in the treatment of intra-cranial aneurysms by endovascular flow diversion: a multicentre prospective study. PLoS One 2010;5 CrossRef Medline

46. Pumar JM, Banguero A, Cuellar H, et al. Treatment of intracranial aneurysms with the Silk Embolization Device in a multicenter study. a retrospective data analysis. Neurosurgery 2017;81:595-601 CrossRef Medline

47. Shankar JJ, Tampieri D, Iancu D, et al. Silk flow diverter for complex intracranial aneurysms: a Canadian registry. J Neurointerv Surg 2016;8:273-78 CrossRef Medline

48. Berge J, Biondi A, Machi P, et al. Flow-diverter Silk stent for the treatment of intracranial aneurysms: 1-year follow-up in a multicenter study. AJNR Am J Neuroradiol 2012;33:1150-55 CrossRef Medline

49. Velioglu M, Kizilkilic O, Selcuk $\mathrm{H}$, et al. Early and midterm results of complex cerebral aneurysms treated with Silk stent. Neuroradiology 2012;54:1355-65 CrossRef Medline

50. Kulcsár Z, Augsburger L, Reymond P, et al. Flow diversion treatment: intra-aneurismal blood flow velocity and WSS reduction are parameters to predict aneurysm thrombosis. Acta Neurochir (Wien) 2012;154:1827-34 CrossRef Medline

51. Bouillot $\mathrm{P}$, Brina $\mathrm{O}$, Ouared $\mathrm{R}$, et al. Computational fluid dynamics with stents: quantitative comparison with particle image velocimetry for three commercial off the shelf intracranial stents. J Neurointerv Surg 2016;8:309-15 CrossRef Medline

52. Bouillot $\mathrm{P}$, Brina $\mathrm{O}$, Ouared $\mathrm{R}$, et al. Hemodynamic transition driven by stent porosity in sidewall aneurysms. J Biomech 2015;48:1300-09 CrossRef Medline

53. Pereira VM, Bonnefous O, Ouared R, et al. A DSA-based method using contrast-motion estimation for the assessment of the intraaneurysmal flow changes induced by flow-diverter stents. AJNR Am J Neuroradiol 2013;34:808-15 CrossRef Medline

54. Bhogal P, Martinez Moreno R, Ganslandt O, et al. Use of flow diverters in the treatment of unruptured saccular aneurysms of the anterior cerebral artery. J Neurointerv Surg 2017;9:283-89 CrossRef Medline

55. Luecking H, Engelhorn T, Lang S, et al. FRED Flow Diverter: a study on safety and efficacy in a consecutive group of 50 patients. AJNR Am J Neuroradiol 2017;38:596-602 CrossRef Medline

56. Gentric JC, Darsaut TE, Makoyeva A, et al. The success of flow diversion in large and giant sidewall aneurysms may depend on the size of the defect in the parent artery. AJNR Am J Neuroradiol 2014;35: 2119-24 CrossRef Medline

57. Killer-Oberpfalzer M, Kocer N, Griessenauer CJ, et al. European multicenter study for the evaluation of a dual-layer flow-diverting stent for treatment of wide-neck intracranial aneurysms: the European Flow-Redirection Intraluminal Device Study. AJNR Am J Neuroradiol 2018;39:841-47 CrossRef Medline

58. Drescher F, Weber W, Berlis A, et al. Treatment of intra- and extracranial aneurysms using the Flow-Redirection Endoluminal Device: multicenter experience and follow-up results. AJNR Am J Neuroradiol 2017;38:105-12 CrossRef Medline

59. Möhlenbruch MA, Herweh C, Jestaedt L, et al. The FRED flow-diverter stent for intracranial aneurysms: clinical study to assess safety and efficacy. AJNR Am J Neuroradiol 2015;36:1155-61 CrossRef Medline

60. Kocer N, Islak C, Kizilkilic O, et al. Flow Re-direction Endoluminal Device in treatment of cerebral aneurysms: initial experience with short-term follow-up results. J Neurosurg 2014;120:1158-71 CrossRef Medline

61. Colby GP, Lin LM, Caplan JM, et al. Flow diversion of large interna carotid artery aneurysms with the Surpass device: impressions and technical nuance from the initial North American experience. J Neurointerv Surg 2016;8:279-86 CrossRef Medline

62. De Vries J, Boogaarts J, Van Norden A, et al. New generation of flow diverter (Surpass) for unruptured intracranial aneurysms: a prospective single-center study in 37 patients. Stroke 2013;44:1567-77 CrossRef Medline

63. Taschner CA, Vedantham S, de Vries J, et al. Surpass flow diverter fo treatment of posterior circulation aneurysms. AJNR Am J Neuroradiol 2017;38:582-89 CrossRef Medline

64. Zhou Y, Yang PF, Fang YB, et al. A novel flow-diverting device (Tubridge) for the treatment of 28 large or giant intracranial aneurysms: a single-center experience. AJNR Am J Neuroradiol 2014;35:2326-33 CrossRef Medline

65. Liu JM, Zhou Y, Li Y, et al; PARAT investigators. Parent artery reconstruction for large or giant cerebral aneurysms using the Tubridge Flow Diverter: a multicenter, randomized, controlled clinical trial (PARAT). AJNR Am J Neuroradiol 2018;39:807-16 CrossRef Medline

66. Fahed R, Raymond J, Ducroux C, et al. Testing flow diversion in animal models: a systematic review. Neuroradiology 2016;58:375-82 CrossRef Medline

67. Akgul E, Onan HB, Akpinar S, et al. The DERIVO Embolization Device in the treatment of intracranial aneurysms: short- and midterm results. World Neurosurg 2016;95:229-40 CrossRef Medline

68. Bouillot $\mathrm{P}$, Brina $\mathrm{O}$, Ouared $\mathrm{R}$, et al. Particle imaging velocimetry evaluation of intracranial stents in sidewall aneurysm: hemodynamic transition related to the stent design. PLoS One 2014;9: e11376 CrossRef Medline

69. Fischer S, Aguilar-Pérez M, Henkes E, et al. Initial experience with 
p64: a novel mechanically detachable flow diverter for the treatment of intracranial saccular sidewall aneurysms. AJNR Am J Neuroradiol 2015;36:2082-89 CrossRef Medline

70. Morais R, Mine B, Bruyère PJ, et al. Endovascular treatment of intracranial aneurysms with the p64 flow diverter stent: mid-term results in 35 patients with 41 intracranial aneurysms. Neuroradiology 2017;59:263-69 CrossRef Medline

71. Chiu AH, De Vries J, O'Kelly CJ, et al. The second-generation eCLIPs endovascular clip system: initial experience. J Neurosurg 2018;128: 482-89 CrossRef Medline

72. Peach T, Cornhill JF, Nguyen A, et al. The 'Sphere': a dedicated bifurcation aneurysm flow-diverter device. Cardiovasc Eng Technol 2014;5:334-47 CrossRef Medline

73 Griessenauer CJ, Ogilvy CS, Adeeb N, et al. Pipeline embolization of posterior circulation aneurysms: a multicenter study of 131 aneurysms. J Neurosurg 2018 Apr 1:1-13 CrossRef Medline 